\title{
SCIENTIFIC REPORTS

\section{OPEN The effect of combined application of Streptomyces rubrogriseus HDZ-9-47 with soil biofumigation on soil microbial and nematode communities}

\begin{abstract}
Na Jin ${ }^{1,2,3}$, Xiuliang Lu ${ }^{1}$, Xueyan Wang ${ }^{1}$, Qian Liu ${ }^{1}$, Deliang Peng ${ }^{2}$ \& Heng Jian $\mathbb{1}^{1^{*}}$
Meloidogyne incognita causes significant damage to many different crops. Previous studies showed that Streptomyces rubrogriseus HDZ-9-47 is a promising biocontrol agent. Combining it with biofumigation improved its efficacy against $M$. incognita. In the present study, the reason for the improved efficacy of the combination was investigated by analyzing its impact on both the soil microbial and the nematode communities in the field. The results showed that the combined application reduced root galls by $41 \%$ and its control efficacy was greater than each treatment alone. Cultivation-based analyses showed that the combination treatment affected the soil microbial community. Actinomycetes and bacterial densities were negatively correlated with the root knot score. In contrast, the fungal densities were positively correlated with the root knot score. Denaturing gradient gel electrophoresis (DGGE) results showed that the combination of S. rubrogriseus HDZ-9-47 and biofumigation enriched beneficial microbes and reduced certain soil-borne fungal phytopathogens, thereby enhancing the efficacies of both S. rubrogriseus HDZ-9-47 and biofumigation against $M$. incognita. And HDZ-9-47 could colonize in soil. The total abundance of nematode and plant parasites, the ratio of soil fungivore nematode to fungivore plus bacterivore nematode, and the nematode diversity indices all decreased with the combination treatment. Overall, the results of this study demonstrate that combined application of HDZ-9-47 with biofumigation was a useful and effective approach to suppress $M$. incognita by manipulating soil microbial communities in field.
\end{abstract}

Meloidogyne incognita is a serious agricultural pest. It attacks a wide range of crops and causes dramatic yield losses ${ }^{1}$. For decades, $M$. incognita was controlled mainly with chemical nematicides. However, most of these products have been banned because of their toxicity to soil ecosystems and human health. Therefore, safe, alternative control methods to $M$. incognita are urgently required. Biocontrol is an attractive nematode management strategy ${ }^{2}$.

Microorganisms are rich natural sources of nematode biocontrol agents. Streptomyces play important roles in controlling plant parasitic nematodes ${ }^{3,4}$. Rashad et al. isolated 112 Streptomycetes from 20 marine samples. Twenty-eight strains exhibited nematicidal activity in vitro and under greenhouse conditions ${ }^{3}$. Until now, however, only a few biocontrol agents have ever been commercialized and applied on a large scale in the field ${ }^{5}$. A crucial limiting factor of the successful field application of biocontrol agents is their inconsistent performance under various environmental conditions ${ }^{6}$. However, applying biocontrol agents in combination with soil biofumigation may solve this problem ${ }^{7}$. Li et al. reported that combining soil biofumigation with antagonistic Pseudomonas reinekei SN21 was highly effective against $M$. incognita in the field ${ }^{8}$. Biofumigation applied as soil incorporation of cabbage residues with subsequent water saturation of the soil and coverage with plastic foil, in combination with the biocontrol strain Streptomyces rubrogriseus HDZ-9-47 was more effective against $M$. incognita than the

${ }^{1}$ Key Laboratory of Pest Monitoring and Green Management, Ministry of Agriculture, Department of Plant Pathology, China Agricultural University, Beijing, 100193, China. ${ }^{2}$ State Key Laboratory for Biology of Plant Diseases and Insect Pests, Institute of Plant Protection, Chinese Academy of Agricultural Sciences, Beijing, 100193, China. ${ }^{3}$ Department of Horticulture, Beijing Vocational College of Agriculture, Beijing, 102442, China. *email: hengjian@cau.edu.cn 


\begin{tabular}{|l|l|l|}
\hline \multirow{2}{*}{ Treatment } & \multicolumn{2}{|l|}{$\mathbf{9 0}$} \\
\cline { 2 - 3 } & ${ }^{\text {e}}$ Root gall score & Root gall reduction \\
\hline${ }^{\mathrm{a}} \mathrm{C}-\mathrm{H}$ & $4.47 \pm 1.50 \mathrm{a}$ & $41 \% \mathrm{a}$ \\
\hline${ }^{\mathrm{b}} \mathrm{H}$ & $7.00 \pm 0.53 \mathrm{~b}$ & $8 \% \mathrm{~b}$ \\
\hline${ }^{\mathrm{c}} \mathrm{C}$ & $5.33 \pm 1.21 \mathrm{a}$ & $30 \% \mathrm{a}$ \\
\hline${ }^{\mathrm{d}} \mathrm{CK}$ & $7.60 \pm 0.35 \mathrm{~b}$ & - \\
\hline
\end{tabular}

Table 1. Effect of the combination of HDZ-9-47 and soil biofumigation on Meloidogyne incognita control

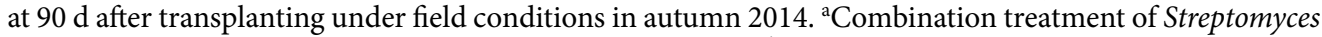
rubrogriseus HDZ-9-47 and soil biofumigation with cabbage. ${ }^{\text {bHDZ-9-47. }}$ 'Soil biofumigation with cabbage. ${ }^{\mathrm{d}}$ Equal volume of water without nematicide or biocontrol agent. ${ }^{\mathrm{e}}$ Root gall was assessed using a 0-10 rating scale according to Bridge and Page (1980). Data are means \pm SD for 15 replications. Means followed by different letters in the same columns are significantly different from each other at the 0.05 probability level according to Tukey's test.

nematicide fosthiazate in a field trial ${ }^{9}$. However, the reason of improved efficacy of the combination of biocontrol agents with biofumigation against $M$. incognita are poorly known.

Once its materials are incorporated into the soil, biofumigation enriches soil carbon and nitrogen and may alter soil microbial and nematode community structure ${ }^{10-12}$. Biocontrol agents may also affect indigenous microbial and nematode community composition ${ }^{13}$. Soil microbes and nematodes usually play important roles in agro-ecosystems. They influence soil nutrient cycling, organic matter formation and decomposition, soil structure, and plant systemic resistance. They may also suppress plant pathogens ${ }^{14}$. Biocontrol agents utilize the carbon and nitrogen provided by biofumigation, thereby increasing their viability and competitiveness in the soil ${ }^{14}$. The application of antagonistic Bacillus amyloliquefaciens strain BS211 with biofumigation affected certain microbial densities, increased soil bacterial diversity, and suppressed Phytophthora blight in pepper ${ }^{15}$. Valdes et al. found that soil biofumigation decreased plant parasitic nematode densities while increasing those of bacterivorous nematodes $^{16}$. So, analyzing the effects of combined application of biocontrol agents with biofumigation on the soil microbial and the nematode communities is helpful for understanding the mechanism of improved performance in field.

The potential environmental risks of introducing biocontrol agents have seldom been studied ${ }^{17}$. The introduction of biocontrol agents may perturb indigenous microbial densities ${ }^{13}$. Before deploying the combination of biocontrol agents and biofumigation on a large scale, it is necessary to assess their impact on soil microbial communities.

Streptomyces rubrogriseus HDZ-9-47 was isolated from the eggs of Meloidogyne sp. ${ }^{18}$. Our earlier study showed that HDZ-9-47 together with biofumigation reduced $M$. incognita in the field ${ }^{9}$. In the present study, the effects of the combined application of HDZ-9-47 with biofumigation on soil microbial and nematode communities were investigated. The results will help to improve the field efficiency of biocontrol agent against M. incognita.

\section{Results}

S. rubrogriseus HDZ-9-47 combined with soil biofumigation improves control efficacy against $M$. incognita. Efficacies of the various treatments against $M$. incognita are showed in Table 1 . The root gall scores in the biofumigation and combination treatments were significantly lower than that of the untreated control at $90 \mathrm{~d}$ after transplanting $(P<0.05$, Table 1$)$. Therefore, combination of HDZ-9-47 with biofumigation could control M. incognita in the field.

Effect of the combination of HDZ-9-47 and biofumigation on the soil microbial community. The cultivable method analysis showed that the bacterial, fungal, and actinomycetes densities did not significantly differ among treatments before biofumigation (Fig. 1).

As showed in Fig. 1A, the culturable bacterial densities in the combined application of HDZ-9-47 with biofumigation treatment and biofumigation alone treatment were significantly lower than that in the control treatment after biofumigation $(P<0.05)$. At 30 and $60 \mathrm{~d}$ post transplantation, the culturable bacterial densities in the application of HDZ-9-47 or biofumigation alone or combination treatments were significantly higher than that in the control treatment, and those in the application HDZ-9-47 alone and combined with biofumigation treatments were significantly higher than that in the biofumigation alone treatment $(P<0.05)$. At $90 \mathrm{~d}$ post transplantation, the culturable bacterial density in the combination treatment was significantly lower than other treatments $(P<0.05)$. At $120 \mathrm{~d}$ post transplantation, the culturable bacterial density in each treatment showed no significantly difference $(P>0.05)$. The results indicated that soil biofumigation decreased the culturable bacterial densities, and application of HDZ-9-47 alone or combined with biofumigation increased the culturable bacterial densities at the early stage of tomato growth.

After biofumigation, the culturable fungal density in the combined application of HDZ-9-47 with biofumigation treatment or biofumigation alone treatment were significantly lower than that of the control, respectively $(P<0.05$, Fig. 1B). At 30 and $60 \mathrm{~d}$ post transplantation, the culturable fungal densities in the application of HDZ-9-47 or biofumigation alone or combination treatments were significantly lower than that of the control, respectively $(P<0.05$, Fig. 1B). At 90 and $120 \mathrm{~d}$ post transplantation, the culturable fungal density showed no significantly difference among treatments $(P>0.05$, Fig. 1B). The results indicated that soil biofumigation and application of HDZ-9-47 decreased the culturable fungal densities in the early stage of tomato growth. 

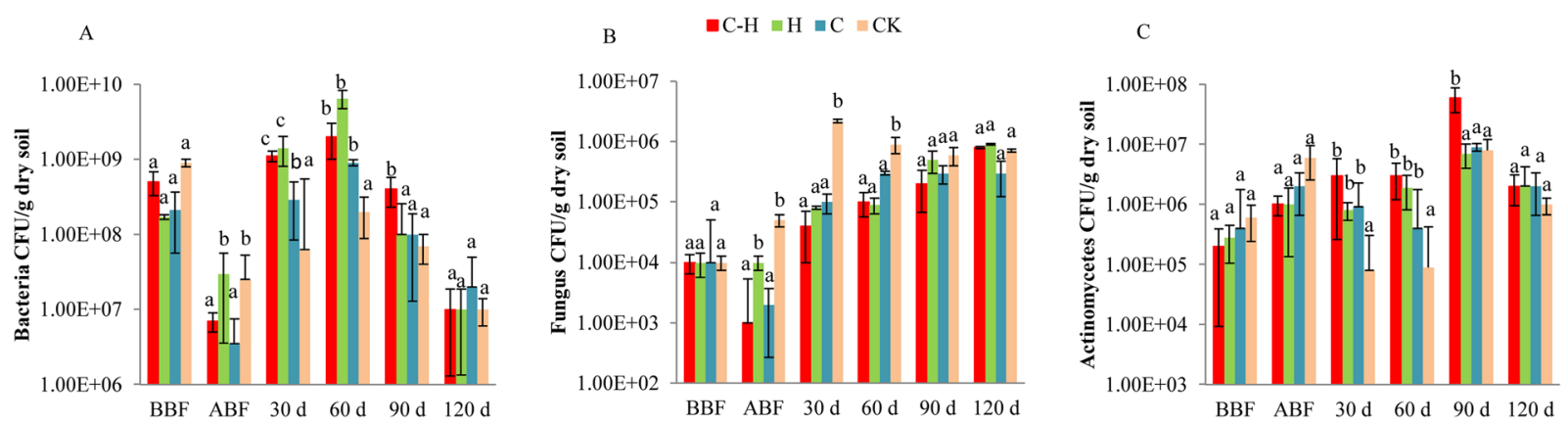

Figure 1. Effect of combination of HDZ-9-47 and biofumigation on the densities of soil culturable bacteria (A), fungi (B), and actinomycetes (C) at different sampling times. C-H: combined applications of Streptomyces rubrogriseus HDZ-9-47 and cabbage biofumigation. H: application of HDZ-9-47 alone. C: soil biofumigation with cabbage. BBF and ABF: before- and after biofumigation, respectively. Error bars represent standard deviation. The different letters on each bar within same sampling time represent significant differences at the 0.05 level based on Tukey's multiple comparison test.

Actinomycetes densities did not significantly differ among treatments after biofumigation $(P>0.05$, Fig. 1C). At 30 and $60 \mathrm{~d}$ post transplantation, the culturable actinomycetes density was significantly higher than that of the control $(P<0.05$, Fig. 1B). At $90 \mathrm{~d}$ post transplantation, the culturable actinomycetes density in the combination treatment was significantly higher than other treatments $(P<0.05$, Fig. $1 \mathrm{~B})$. At $120 \mathrm{~d}$ post transplantation, the culturable actinomycetes density showed no significantly difference among treatments $(P>0.05$, Fig. 1B). The results indicated that soil biofumigation and application of HDZ-9-47 increased the culturable actinomycetes densities in the early stage of tomato growth.

Correlation analysis showed that the culturable bacterial density was negatively correlated with the root knot score at $90 \mathrm{~d}$ after transplanting $\left(r=-0.445^{*} ; P<0.05\right)$, and the culturable fungal density was significantly positively correlated with the root knot score at $90 \mathrm{~d}$ after transplanting $\left(r=0.535^{*} ; P<0.05\right)$.

The effects of all treatments on the soil bacterial and fungal communities were further analyzed by PCR-DGGE using three replications per treatment. Certain bands were common to all treatments after biofumigation (Fig. 2A,D). These included the bacterial bands BF1, BF2, BF3 and the fungal bands AF1, AF2, AF3, AF4, AF5, and AF6 (Fig. 2A,D, Tables 2 and 3). Therefore, these soil bacteria and fungus were stable and unaffected by biofumigation.

At $30 \mathrm{~d}$ after transplanting, the bacterial band BT2 and the fungal bands AT1 and AT3 were found only in the combination treatment. However, the bacterial bands BT1, BT3, and BT4 were absent in this treatment (Fig. 2B). A bacterial band BT5 with the same electrophoretic mobility as the 16S rRNA gene fragment of HDZ-9-47 was present in both the HDZ-9-47 and combination treatments. Therefore, HDZ-9-47 may have colonized in soil (Fig. 2B).

At $120 \mathrm{~d}$ after transplanting, the DGGE bands were similar for all treatments but could still be differentiated by the presence of weak bands. As showed in Fig. 2C,F, the DGGE bands in the combination treatment differed from those of the other treatments. The new bacterial bands BHA1, BHA2, BHA3, BHA4 and the fungal bands AHA1, AHA3, AHA5, AHA7 appeared whereas the fungal bands AHA2, AHA4, and AHA6 vanished in the combination treatment. The bacterial band BHA5 with the same electrophoretic mobility as the $16 \mathrm{~S}$ rRNA gene fragment of HDZ-9-47 was present in the HDZ-9-47 and combination treatments. Therefore, HDZ-9-47 remained stable in the soil at $120 \mathrm{~d}$ after transplanting (Fig. 2C).

Effect of the combination of HDZ-9-47 and biofumigation on the soil nematode community. A total of 26 nematode genera belonging to 12 families were detected in the soil samples. These included 9 plant parasite, 12 bacterivore, 3 fungivore, and 2 predator/omnivore genera (Table 4 ).

The abundance of total nematodes, plant parasites and bacterivores did not significantly differ among treatments before and immediately after biofumigation $(P>0.05$, Fig. 3$)$. However, the abundance of fungivores was significantly reduced after biofumigation $(P<0.05$, Fig. $3 \mathrm{c})$. The abundances of plant parasites in the combination treatment and biofumigation alone treatment were significantly lower than those in HDZ-9-47 alone treatment and the untreated control at $30 \mathrm{~d}, 60 \mathrm{~d}, 90 \mathrm{~d}$, and $120 \mathrm{~d}$ after transplanting, respectively $(P<0.05$, Fig. 3B). And the abundances of fungivores in application HDZ-9-47 and biofumigation alone and combination treatments were significantly lower than those in the untreated control at $30 \mathrm{~d}, 60 \mathrm{~d}, 90 \mathrm{~d}$, and $120 \mathrm{~d}$ after transplanting $(P<0.05$, Fig. 3C). The abundances of bacterivores and predators/omnivores were not significantly affected by any treatment $(P>0.05$, Fig. 3D,E).

The ratio of fungivores to fungivores plus bacterivores $[F /(F+B)]$ indirectly reflects organic matter decomposition and carbon and nitrogen mineralization in the soi ${ }^{19}$. The combination treatment significantly reduced $F /(F+B)$ relative to the untreated control immediately after biofumigation $(A B F)$ and at $30 \mathrm{~d}, 60 \mathrm{~d}, 90 \mathrm{~d}$, and 120 $\mathrm{d}$ after transplanting $(P<0.05$, Fig. 4). The results suggest that the combination treatment accelerates organic matter decomposition and nutrient turnover in the soil.

The Shannon diversity $\left(H^{\prime}\right)$, Pielou evenness $\left(E_{H}\right)$, and Margalef richness $(S R)$ indices for the soil nematodes decreased with sampling time in all treatments (Fig. 5). $H^{\prime}$ for the combination treatment was significantly lower than that for the untreated control at $120 \mathrm{~d}$ after transplanting $(P<0.05$, Fig. $5 \mathrm{~A})$. $S R$ was also significantly lower for 

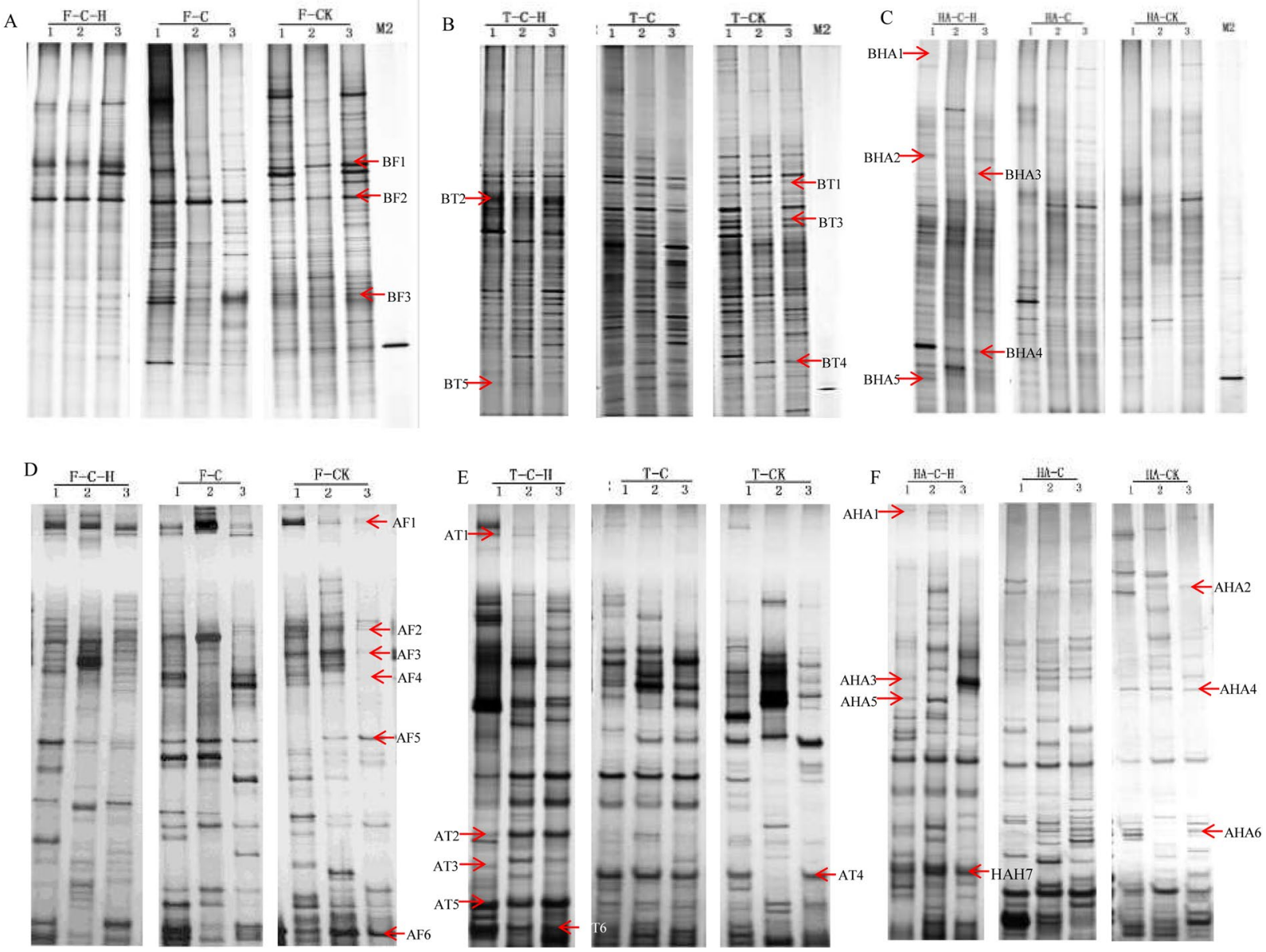

Figure 2. DGGE patterns of bacterial $16 \mathrm{~S}$ rDNA genes (A-C) and fungal ITS (D-F) in different treatments immediately after biofumigation $(\mathbf{A}, \mathbf{D})$, and at $30 \mathrm{~d}(\mathbf{B}, \mathbf{E})$ and $120 \mathrm{~d}(\mathbf{C}, \mathbf{F})$ after transplanting. C-H: combination of Streptomyces rubrogriseus HDZ-9-47 and biofumigation by cabbage. H: application of HDZ-9-47 alone. C: soil biofumigation with cabbage. M2: marker of a PCR product obtained from HDZ-9-47. F, T, and HA: samples collected before biofumigation and at $30 \mathrm{~d}$ and $120 \mathrm{~d}$ after transplanting, respectively. All images in this figure were partly selected from original images of DGGE assays on bacteria and fungi and spliced together.

\begin{tabular}{|l|l|l|l|}
\hline Band Number & Accession number & Similar strain & Classification \\
\hline Band BF1 & MK277303 & uncultured Planomicrobium sp. & Firmicutes \\
\hline Band BF2 & MK277304 & Oxalobacteraceae bacterium & Proteobacteria \\
\hline Band BF3 & MK277303 & uncultured gamma proteobacterium & Proteobacteria \\
\hline Band BT1 & MK277310 & Oxalobacteraceae bacterium & Proteobacteria \\
\hline Band BT2 & MK277311 & uncultured bacterium & Bacteria; environmental samples \\
\hline Band BT3 & MK277312 & uncultured Fictibacillus sp. & Firmicutes \\
\hline Band BT4 & MK277313 & uncultured Sphingomonas sp. & Proteobacteria \\
\hline Band BT5 & MK277314 & uncultured Actinomycetales bacterium & Actinobacteria \\
\hline Band BHA1 & MK277305 & uncultured Escherichia sp. & Proteobacteria \\
\hline Band BHA2 & MK277306 & uncultured Shigella sp. & Proteobacteria \\
\hline Band BHA3 & MK277307 & Paenisporosarcina sp. & Firmicutes \\
\hline Band BHA4 & MK277308 & Streptomyces sp. & Actinobacteria \\
\hline Band BHA5 & MK277309 & uncultured Actinomycetales bacterium & Actinobacteria \\
\hline
\end{tabular}

Table 2. Identification of selected bacterial $16 \mathrm{~S}$ rDNA sequences and their GenBank accession numbers.

the combination treatment than the untreated control at $60 \mathrm{~d}, 90 \mathrm{~d}$, and $120 \mathrm{~d}$ after transplanting $(P<0.05$, Fig. 5C). However, $E_{H}$ was not significantly affected by the combination treatment relative to the control $(P>0.05$, Fig. $5 \mathrm{~B})$.

The maturity index $(M I)$ represented the nematode community structure. $M I$ is a measure of disturbance. $M I$ decreases with increasing environmental disturbance. The plant parasitic index $(P P I)$ increases with agricultural 


\begin{tabular}{|l|l|l|l|}
\hline Band Number & Accession number & Similar strain & Classification \\
\hline Band AF1 & MK294736 & uncultured Ascomycota & Ascomycota \\
\hline Band AF2 & MK294737 & Thielavia sp. & Ascomycota \\
\hline Band AF3 & MK294738 & uncultured Pseudeurotium & Ascomycota \\
\hline Band AF4 & MK294739 & Pleosporales sp. & Ascomycota \\
\hline Band AF5 & MK294740 & uncultured Thielavia & Ascomycota \\
\hline Band AF6 & MK294741 & Pyronemataceae sp. & Ascomycota \\
\hline Band AT1 & MK294749 & uncultured fungus & Fungi; environmental samples \\
\hline Band AT2 & MK294750 & Cladosporium sp. & Ascomycota \\
\hline Band AT3 & MK294751 & uncultured Basidiomycota & Basidiomycota \\
\hline Band AT4 & MK294752 & Davidiella tassiana & Ascomycota \\
\hline Band AT5 & MK294753 & uncultured Ascomycota & Ascomycota; \\
\hline Band AT6 & MK294754 & uncultured fungus & Fungi; environmental samples \\
\hline Band AHA1 & MK294742 & Pyronemataceae sp. & Ascomycota \\
\hline Band AHA2 & MK294743 & uncultured Ascomycota & Ascomycota \\
\hline Band AHA3 & MK294744 & Eurotiales sp. & Ascomycota \\
\hline Band AHA4 & MK294745 & Geomyces sp. & Geomyces \\
\hline Band AHA5 & MK294746 & Thielavia sp. & Ascomycota \\
\hline Band AHA6 & MK294747 & uncultured Rhizoctonia & Basidiomycota \\
\hline Band AHA7 & MK294748 & uncultured fungus & Fungi; environmental samples \\
\hline
\end{tabular}

Table 3. Identification of selected fungal ITS sequences and their GenBank accession numbers.

enrichment. Nutrient enrichments could reduce $P P I / M I$. In our experiment, however, $M I, P P I$, and $M I / P P I$ were not significantly affected by any treatment at any sampling time $(P>0.05$, Fig. 5D-F).

\section{Discussion}

The combined application of S. rubrogriseus HDZ-9-47 and biofumigation had superior efficacy against $M$. incognita compared with either treatment alone ${ }^{9}$. In our early report, the reduction rates of root-knot index in combined application of HDZ-9-47 with biofumigation, HDZ-9-47 alone, and biofumigation alone treatments were 87.1, 45.7, and 61.4 at $90 \mathrm{~d}$ post transplantation, respectively. And the reduction percentages of J2s density in those treatments were 91.0,69.7, and 77.8, respectively 9 . In the present study, the combined application reduced root galls by $41 \%$ and its control efficacy was greater than each treatment alone. This finding corroborates those of previous reports.

The soil microbial community plays an important role in disease control. Beneficial soil microbes may help suppress plant pathogens $\mathrm{s}^{20,21}$. Wang et al. reported that integrating biofumigation with antagonistic microorganisms controls Phytophthora blight by regulating soil bacterial community structure ${ }^{15}$. In this study, we hypothesized that the gains in efficacy against $M$. incognita realized by the combination of S. rubrogriseus HDZ-9-47 and biofumigation are associated with their effects on the soil microbial community. Cultivation-based analyses showed that at $30 \mathrm{~d}$ and $60 \mathrm{~d}$ after transplanting, the soil culturable bacterial and actinomycetes densities increased in response to HDZ-9-47, biofumigation, and especially the combination of the two. The culturable actinomycetes and bacterial densities were negatively correlated with root gall score. Our PCR-DGGE analysis showed the bacterial bands BHA4 (Streptomyces sp.) only appeared in the combination treatment. Actinomycetes may produce various secondary metabolites with nematicidal activity to help control plant parasitic nematodes. Streptomyces is the major actinomycetes genus. Its member species control plant parasitic nematodes by antagonism or parasitism ${ }^{3,4}$. Sun et al. (2006) reported that a total of 52 actinomycetes isolates were obtained from eggs and females of Meloidogyne spp. Most of these isolates could parasitize eggs of Meloidogyne hapla, inhibit egg hatch, and kill second-stage juveniles (J2s) in vitro. In the combination treatment, the fungal band FHA6 (Rhizoctonia sp.) disappeared. Earlier studies showed that most Rhizoctonia sp. are globally distributed soil-borne fungi which can infect many economically important field crops ${ }^{22}$. Cultivation-based analysis showed that the fungal density was positively correlated with the root gall number and decreased in the HDZ-9-47, biofumigation, and combination treatments relative to the control. These results suggest that the combination of S. rubrogriseus HDZ-9-47 and biofumigation promoted the reproduction of some fungal species. The combination treatment enriched beneficial microbes and reduced certain soil-borne fungal phytopathogens, thereby enhancing the efficacy of both S. rubrogriseus HDZ-9-47 and biofumigation against M. incognita. A previous report indicated that the abundance of beneficial microbes was higher in response to the combined application of lime, ammonium bicarbonate, and bioorganic fertilizer than the control treatment ${ }^{23}$. Certain studies observed increases in bacterial densities and decreases in fungal densities after the introduction of biocontrol agents like Beauveria bassiana or Pseudomonas fluorescens $2 \mathrm{P} 24^{24,25}$. Ascencion et al. found that the soil fungal density was positively correlated with the incidence of Rhizoctonia solani damping-off disease. In contrast, the soil actinomycetes density was negatively correlated with damping-off after biofumigation with Brassica $^{26}$.

The soil nematode community is an indicator of environmental changes caused by agricultural practices ${ }^{27,28}$. In this study, the abundance of fungivores was significantly reduced after biofumigation $(P<0.05)$. Wang G, et al. (2009) also found that Brassica biofumigants reduced the fungivores in the soil. Relative to the control in the 


\begin{tabular}{|c|c|c|c|c|c|}
\hline Nematode taxa & ${ }^{\mathrm{a}} \mathrm{c}-\mathrm{p}$ & ${ }^{b} \mathrm{C}-\mathrm{H}$ & ${ }^{\mathrm{c}} \mathrm{H}$ & ${ }^{\mathrm{d}} \mathrm{C}$ & ${ }^{\mathrm{e}} \mathrm{CK}$ \\
\hline Plant parasites & & - & - & - & - \\
\hline Tylenchida & & - & - & - & - \\
\hline Heteroderidae & & - & - & - & - \\
\hline Meloidogyne & 3 & 5,172 & 12,539 & 7,173 & 10,426 \\
\hline Heterodera & 3 & 0 & 5 & 34 & 0 \\
\hline Tylenchidae & & - & - & - & - \\
\hline Psilenchus & 2 & 2 & 5 & 4 & 1 \\
\hline Tylenchus & 2 & 2 & 19 & 1 & 27 \\
\hline Lelenchus & 2 & 0 & 0 & 0 & 0 \\
\hline Filenchus & 2 & 21 & 35 & 14 & 52 \\
\hline Helicotylenchus & 3 & 0 & 0 & 0 & 1 \\
\hline Criconematidae & - & - & - & - & - \\
\hline Criconemella & 3 & 0 & 0 & 0 & 0 \\
\hline Dorylaimida & - & - & - & - & - \\
\hline Longidoridae & - & - & - & - & - \\
\hline Longidorella & 4 & 0 & 0 & 1 & 1 \\
\hline Bacterivores & - & - & - & - & - \\
\hline Rhabditida & - & - & - & - & - \\
\hline Cephalobidae & - & - & - & - & - \\
\hline Chiloplacus & 2 & 33 & 49 & 69 & 72 \\
\hline Acrobeles & 2 & 0 & 0 & 0 & 3 \\
\hline Cervidellus & 2 & 2 & 11 & 8 & 29 \\
\hline Arcobeloides & 2 & 2 & 0 & 0 & 1 \\
\hline Cephalobus & 2 & 281 & 127 & 174 & 224 \\
\hline Eucephalobus & 2 & 2 & 52 & 12 & 54 \\
\hline Rhabditidae & - & - & - & - & - \\
\hline Pelodera & 1 & 7 & 15 & 2 & 19 \\
\hline Rhabditis & 1 & 69 & 64 & 49 & 43 \\
\hline Protorhabditis & 1 & 15 & 120 & 63 & 178 \\
\hline Panagrolaimidae & - & - & - & - & - \\
\hline Panagrolaimus & 1 & 3 & 3 & 11 & 36 \\
\hline Mononchida & - & - & - & - & - \\
\hline Monhysteridae & - & - & - & - & - \\
\hline Prismatolainus & 1 & 47 & 183 & 55 & 166 \\
\hline Geomonhystera & 2 & 5 & 12 & 6 & 16 \\
\hline Fungivores & - & - & - & - & - \\
\hline Aphelenchida & - & - & - & - & - \\
\hline Aphelenchidae & - & - & - & - & - \\
\hline Aphelenchus & 2 & 37 & 110 & 32 & 167 \\
\hline Tylenchida & - & - & - & - & - \\
\hline Aphelenchoididae & - & - & - & - & - \\
\hline Aphelenchoides & 2 & 2 & 0 & 0 & 5 \\
\hline Anguinidae & - & - & - & - & - \\
\hline Ditylenchus & 2 & 0 & 0 & 1 & 32 \\
\hline Predators/Omnivores & - & - & - & - & - \\
\hline Dorylaimida & - & - & - & - & - \\
\hline Dorylaimidae & - & - & - & - & - \\
\hline Aporcelaimus & 5 & 9 & 17 & 1 & 16 \\
\hline Eudorylaimus & 4 & 24 & 64 & 33 & 73 \\
\hline
\end{tabular}

Table 4. Effects of combined application of HDZ-9-47 and biofumigation on nematode taxa. ${ }^{\text {aC }}$ Corresponding to their positions along the colonizer-persister continuum of their life-histories. ${ }^{\mathrm{b}}$ Combination of Streptomyces rubrogriseus HDZ-9-47 and cabbage biofumigation. ${ }^{c} \mathrm{HDZ}-9-47$ alone. ${ }^{\mathrm{d} S}$ Soil biofumigation with cabbage. ${ }^{\mathrm{e}}$ Equal volume of water without nematicide or biocontrol agent.

present study, the abundance of plant parasites was not significantly reduced immediately after biofumigation $(P>0.05)$, but was significantly decreased in response to the combination and biofumigation alone treatments at $30 \mathrm{~d}, 60 \mathrm{~d}, 90 \mathrm{~d}$, and $120 \mathrm{~d}$ after transplanting. However, the abundances of omnivorous/predaceous nematodes 
A

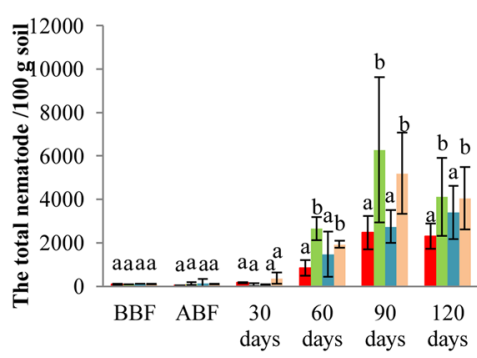

B

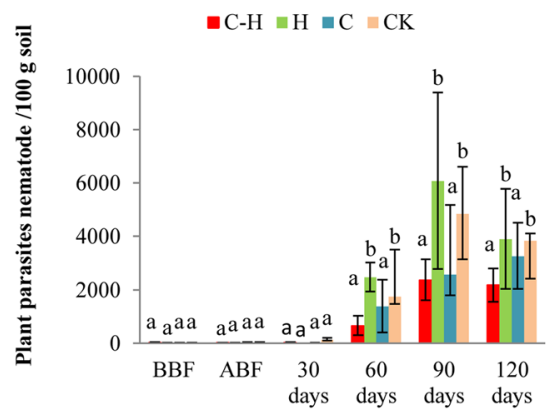

$\mathrm{C}$

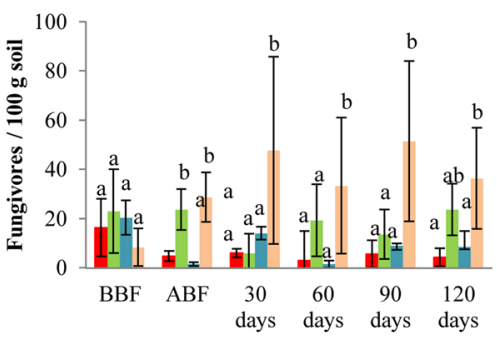

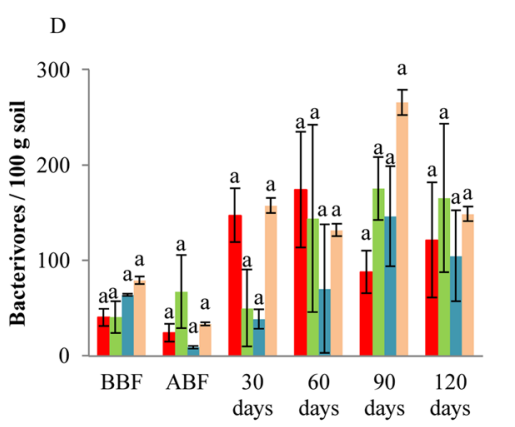

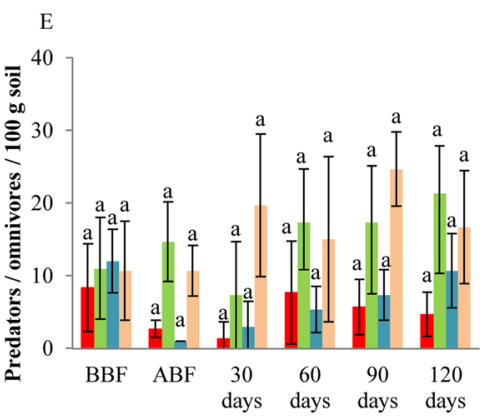

Figure 3. Effect of the combination of HDZ-9-47 and biofumigation on the abundance of soil total nematodes (A), plant parasites (B), fungivores $(\mathbf{C})$, bacterivores $(\mathbf{D})$, and predators/omnivores $(\mathbf{E})$ at different sampling dates. C-H: combination of Streptomyces rubrogriseus HDZ-9-47 and biofumigation with cabbage. $\mathrm{H}$ : application of HDZ-9-47 alone. C: soil biofumigation with cabbage. BBF and ABF: before- and after biofumigation, respectively. Error bars represent standard deviation. The different letters on each bar within same sampling time represent significant differences at the 0.05 level based on Tukey's multiple comparison test.

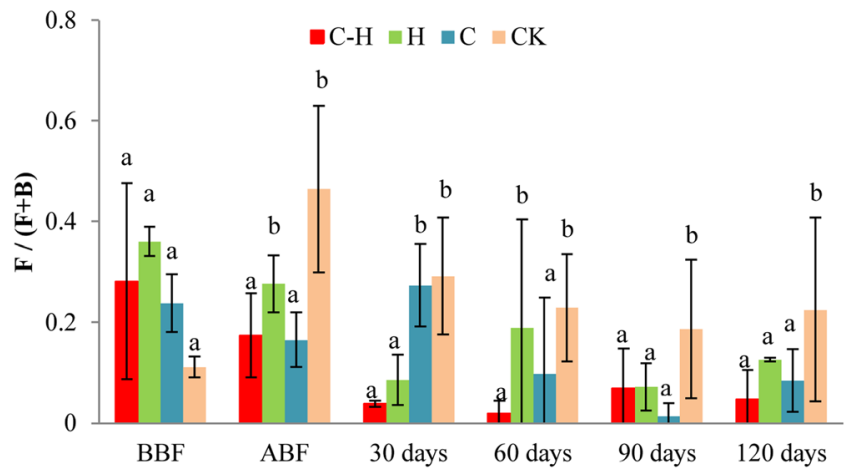

Figure 4. Effect of the combination of HDZ-9-47 and biofumigation on the ratio of fungivore to fungivore plus bacterivore, $F /(F+B)$. C-H: combination of Streptomyces rubrogriseus HDZ-9-47 and biofumigation with cabbage. H: application of HDZ-9-47 alone. C: soil biofumigation with cabbage. BBF and ABF: before- and after biofumigation, respectively. Error bars represent standard deviation. The different letters on each bar within same sampling time represent significant differences at the 0.05 level based on Tukey's multiple comparison test.

were not affected by this treatment. Therefore, the decline in plant parasites was not attributed to toxic volatile compounds produced by biofumigation or top-down control by predator nematodes ${ }^{29}$. Gruver et al. found that biofumigation did not influence the abundances of omnivores/predators ${ }^{30}$. The ratio of fungivores to fungivores plus bacterivores $[F /(F+B)]$ indirectly reflects organic matter decomposition and carbon and nitrogen mineralization in the soil ${ }^{19}$. The combination treatment significantly reduced $F /(F+B)$ compared with the untreated control. Therefore, there may have been high organic matter decomposition rates and fast nutrient turnover in this treatment. The nematode diversity index has been commonly used to assess the impact of human intervention on the nematode community ${ }^{10}$. Our previous trials in Tong zhou district of Beijing showed that the combined application of HDZ-9-47 with biofumigation reduced the abundances of total nematodes and plant parasites, and decreased the $S R$ of the soil nematodes $(P<0.05)$. And the combination treatment had no significant effect on $M I, P P I$, or $M I / P P I(P>0.05)$. Our current field trial presented with similar results. Earlier studies reported that the nematode diversity index increased in fields treated with biofumigation relative to the control ${ }^{31,32}$. However, 

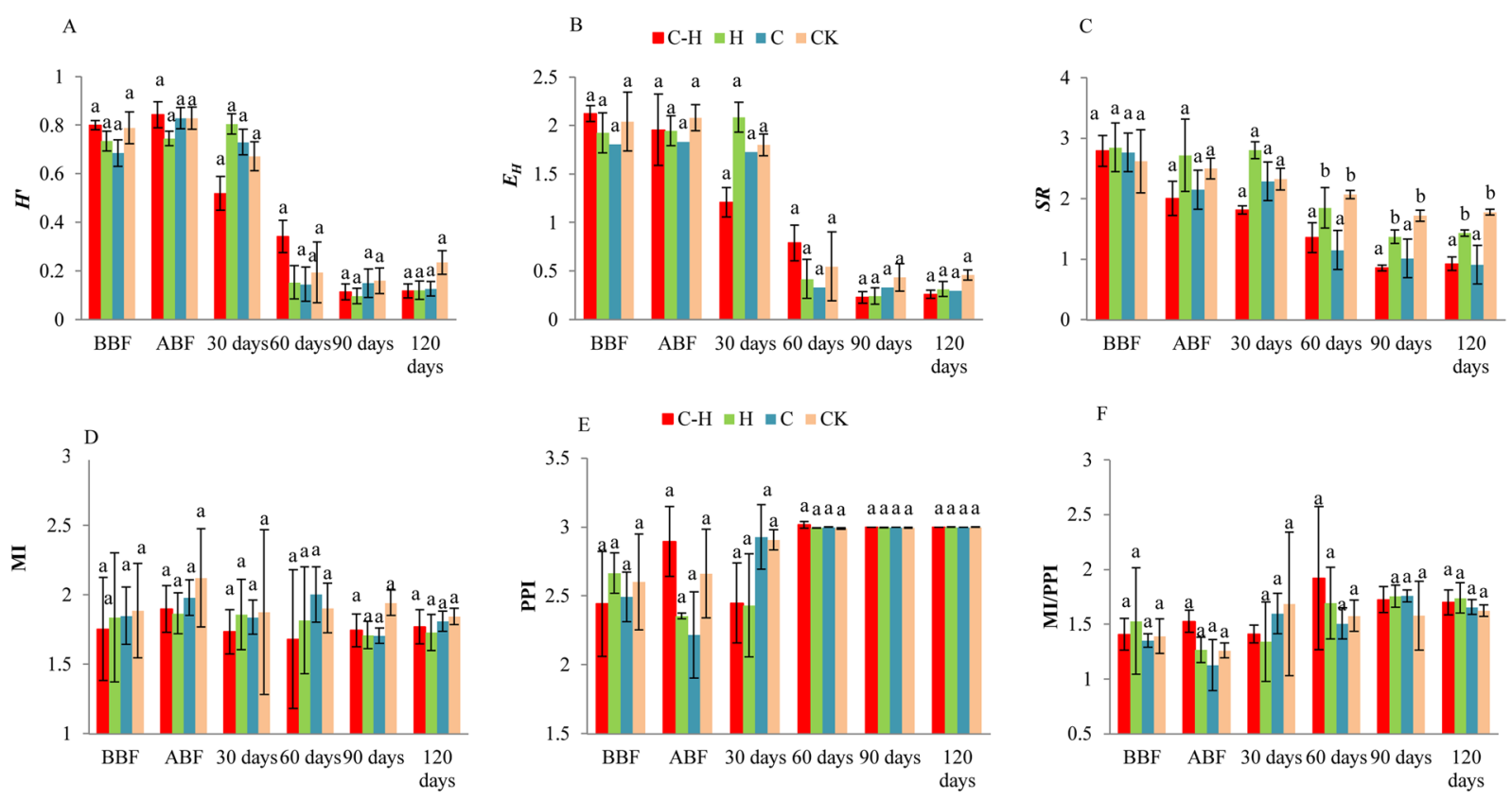

Figure 5. Effect of combination treatment of HDZ-9-47 and biofumigation on the Shannon diversity $\left(H^{\prime}\right)$ $(\mathbf{A})$, Pielou evenness $\left(E_{H}\right)(\mathbf{B})$, Margalef richness $(S R)(\mathbf{C})$, and maturity indices of free-living nematodes $(M I$, D), plant parasitic nematodes $(P P I, \mathbf{E})$ and $M I / P P I(P P I, \mathbf{F})$ at different sampling dates. C-H: combination of Streptomyces rubrogriseus HDZ-9-47 and biofumigation with cabbage. H: HDZ-9-47 alone. C: soil biofumigation with cabbage. BBF and ABF: before- and after biofumigation, respectively. Error bars represent standard deviation. The different letters on each bar within same sampling time represent significant differences at the 0.05 level based on Tukey's multiple comparison test.

this effect was not observed in the present study. In contrast, $H^{\prime}, S R$, and $E_{H}$ ' decreased relative to the control in the combination treatment at $120 \mathrm{~d}$ after transplanting, which is the late stage of tomato growth. This delayed decrease in biodiversity may be explained by the fact that biofumigation alters the soil microbe communities used as food by nematodes. This effect may influence the nematode density.

Biocontrol agents or biofumigation may have short- or long-term effects on soil microbial communities ${ }^{10}$. Some researchers reported only transient effects on soil microbial communities following inoculation with biocontrol agents like Pseudomonas fluorescens 2P24, P. fluorescens CPF10, and Bacillus subtilis $\mathrm{Jdm} 2^{27,33,34}$. The combination of HDZ-9-47 and biofumigation only had an impact on the soil microbial community at the early stages of tomato growth. Our results also showed that the soil microbe community was mainly influenced by plant growth.

Biocontrol agent colonization in the soil is essential for efficacy ${ }^{35}$. The PCR-DGGE analysis identified a strong band (Streptomyces) corresponding to the HDZ-9-47 isolate which was visible in all HDZ-9-47 treatments at $30 \mathrm{~d}$ and $120 \mathrm{~d}$ after transplanting. Therefore, we inferred that HDZ-9-47 may colonize in the soil.

In addition, we applied PCR-DGGE approach to investigate the soil microbial community in this work. PCR-DGGE has been the most applied technique for microbial community studies for a long time; its advantages include the relatively low cost of instrumentation, the possibility of processing several samples altogether and the relative ease of use ${ }^{36}$. However, PCR-DGGE suffers from a number of drawbacks, the main ones being represented by low resolution power, background noises and difficulties in extrapolating quantitative data by the analysis of band intensities ${ }^{36}$. In this work, nested PCR was used to determine the fingerprints of fungi community. The overamplification of 60 cycles may generate the prevalence of some bands over other bands that do not amplify so easily. PCR-DGGE was only used as a tool for analyzing comparative community structure, not as a means of quantifying $\alpha$-diversity ${ }^{37}$. To more deep understand the effect of combined application of HDZ-9-47 with soil biofumigation on soil microbial diversity, high-throughput sequencing technologies (HTS) should be employed in future investigation.

In conclusion, combined application of S. rubrogriseus HDZ-9-47 with biofumigation had significant effects on the soil microbial and nematode communities at the early stages of tomato growth, which contribute to control $M$. incognita through direct and indirect effects. This study provides new insights into the reason of improvement efficacy of the combination against $M$. incognita. In addition, the combination of S. rubrogriseus HDZ-9-47 and biofumigation only have short-term effects on soil microbial communities. To maximize the potential of $S$. rubrogriseus HDZ-9-47 and biofumigation, future work is required to elucidate the effects of biofumigation on $S$. rubrogriseus HDZ-9-47 colonization. 


\section{Materials and Methods}

HDZ-9-47 liquid culture. Streptomyces rubrogriseus HDZ-9-47 was obtained from the Institute of Microbiology of the Chinese Academy of Science and deposited at the China General Microbiological Culture Collection Center as CGMCC 2878. The isolate was cultured in a medium consisting of $1.05 \%$ corn flour, $1.825 \%$ bean flour, $0.22 \% \mathrm{MgSO}_{4} \cdot 7 \mathrm{H}_{2} \mathrm{O}, 0.15 \% \mathrm{~K}_{2} \mathrm{HPO}_{4} \cdot 3 \mathrm{H}_{2} \mathrm{O}, 0.1 \% \mathrm{CaCO}_{3}$, and $0.0238 \% \mathrm{MnSO}_{4}$, w/v (pH 7.3). This formulation was described by Jin et al. ${ }^{9}$.

Field conditions and experiment design. Trials were conducted in a protected field (length $90.0 \mathrm{~m}$; width $5.5 \mathrm{~m})$ in the Chang ping district, Beijing, China $\left(41^{\circ} 2^{\prime} \mathrm{N}, 116^{\circ} 2^{\prime} \mathrm{E}\right)$ in springtime 2014 . The field was naturally infested with $M$. incognita. The soil was a calcareous sandy loam with $\mathrm{pH} 7.13 \pm 0.04$. It contained $15 \mathrm{~g} \mathrm{~kg}^{-1}$ organic matter, $1 \mathrm{~g} \mathrm{~kg}^{-1}$ total nitrogen, $143.9 \mathrm{~g} \mathrm{~kg}^{-1}$ available potassium, and $207.5 \mathrm{~g} \mathrm{~kg}^{-1}$ available phosphorus. The daily air temperature ranged from $15-38^{\circ} \mathrm{C}$. The field was continuously cultivated with tomato (Solanum lycopersicum) and treated with fosthiazate to control root knot nematode for 2-y before the start of our trials.

Thirty-day-old tomato seedlings Cv. Zhefen 702 (susceptible to M. incognita) were transplanted into the field after soil treatment by S. rubrogriseus HDZ-9-47, biofumigation or their combination. The treatments were designed as follows: (1) HDZ-9-47 alone: a $200 \mathrm{ml}$ cultures containing 1012 HDZ-9-47 spores was drenched into the planting hole $(\mathrm{H})$; (2) biofumigation: cabbage residue and $\mathrm{NH}_{4} \mathrm{NO}_{3}$ (Tianjin Tongxin Chemical Co., Ltd., Tianjin, China) were incorporated into the top $20 \mathrm{~cm}$ of the soil at a rate of $3.5 \mathrm{~kg} \mathrm{~m}^{-2}$ and $0.1 \mathrm{~kg} \mathrm{~m}^{-2}$, respectively. Then the soil was irrigated to maximum field capacity with a drip irrigation system and covered with transparent polythene film ( $0.2 \mathrm{~mm}$ thickness) for $20 \mathrm{~d}$ (C), (3) HDZ-9-47 combination with soil biofumigation: a $200 \mathrm{ml}$ cultures containing $10^{12} \mathrm{HDZ}-9-47$ spores was drenched into the planting hole after the soil was biofumigated with $3.5 \mathrm{~kg} / \mathrm{m}^{2}$ cabbage (C-H), (4) untreated control (CK). Details please see the methods descripted by Jin et al. ${ }^{9}$.

The treatments were arranged in a randomized complete block design (RCBD) with three replicates per treatment. Each replicate (length $5.5 \mathrm{~m}$; width $1.5 \mathrm{~m}$ ) consisted of $\geq 32$ plants. The protected field was irrigated by a linear drip irrigation system as required and fertilized in accordance with local growing practices.

Data collection. The soil was sampled 0-20 cm below the rhizosphere surface using a soil corer (diameter: $2 \mathrm{~cm}$; Soil Sampler Inc., Johns Creek, GA, USA) before and after biofumigation at $30 \mathrm{~d}, 60 \mathrm{~d}, 90 \mathrm{~d}$, and $120 \mathrm{~d}$ after transplanting. The samples were stored at $-80^{\circ} \mathrm{C}$ or at $4{ }^{\circ} \mathrm{C}$ for the soil microbial and the soil nematode community tests, respectively. At $90 \mathrm{~d}$ after transplanting, five plants and their rhizosphere soils were collected per treatment. Root galls on nematode-infected plants were assessed with a $0-10$ rating scale according to Bridge and Page ${ }^{38}$. Nematodes in $100 \mathrm{~cm}^{3}$ tomato rhizosphere soil, including $M$. incognita juveniles, were extracted by a modified salt-centrifugal-flotation technique ${ }^{39}$. The recovered nematodes were observed and counted under a compound- or stereoscopic microscope (SZ61; Olympus Corp., Tokyo, Japan).

Cultivation-based analyses of microbial densities. Culturable microbial densities were determined by cultivation-based analyses ${ }^{40}$. Ten grams of rhizospheric soil was mixed with $90 \mathrm{~mL}$ of sterile water in a $200-\mathrm{mL}$ flask by shaking on a rotary shaker for $30 \mathrm{~min}$ at $180 \mathrm{rpm}$. Serial $10 \times$ dilutions were then prepared down to $10^{-7}$. Then $0.1-\mathrm{mL}$ aliquots of the appropriate dilutions were spread on the corresponding media in triplicate. Fungi were cultured on Potato Dextrose Agar (PDA) supplemented with $25 \mathrm{mg} \mathrm{L}^{-1}$ streptomycin sulfate (Sigma Aldrich Chemical, Germany) at $28^{\circ} \mathrm{C}$ for $7 \mathrm{~d}$. Actinomycetes were cultured on Gauze's Agar supplemented with $50 \mathrm{mg} \mathrm{L}^{-1}$ potassium dichromate (Sigma Aldrich Chemical, Germany) at $28^{\circ} \mathrm{C}$ for $7 \mathrm{~d}$. The bacteria were cultured on Luria Bertani Agar (LB) at $37^{\circ} \mathrm{C}$ for $48 \mathrm{~h}$. The colony-forming units (CFU) of the fungi, actinomycetes, and bacteria were then counted.

DNA extraction from soil. Total soil DNA was extracted with a PowerMax ${ }^{\circledR}$ Soil DNA Isolation Kit (MoBio Laboratories, Inc., Solana Beach, CA, USA) following the manufacturer's protocol. The DNA was stored at $-20^{\circ} \mathrm{C}$ until later use.

Polymerase chain reaction (PCR) and denaturing gradient gel electrophoresis (DGGE). The soil bacterial and fungal community structures were determined by PCR-DGGE. The bacterial 16 S rDNA fragment was amplified with the 338f-GC clamp (5'-CCTACGGAGGCAGCAGCGCCCGGGGC GCGCCCCGGGGCGGGGCGGGGGCGCGGGGGG-3')/518r (5'-CCTACGGGAGGCAGCA G-3') primer pair ${ }^{41}$. PCR was run in a $50-\mu \mathrm{L}$ volume consisting of $0.5 \mu \mathrm{L} r$ Taq DNA polymerase (TaKaRa Bio Inc., Kusatsu, Shiga, Japan), $5 \mu \mathrm{L}$ of $10 \times$ PCR buffer (TaKaRa Bio Inc., Kusatsu, Shiga, Japan), $4 \mu \mathrm{L}$ dNTP mix (TaKaRa Bio Inc.,

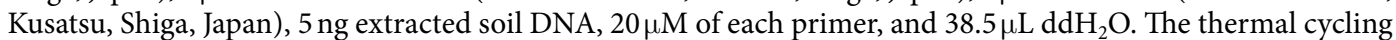
program was as follows: initial denaturation at $94^{\circ} \mathrm{C}$ for $5 \mathrm{~min}$, then 30 cycles of 30 -s denaturation at $94^{\circ} \mathrm{C}$, then $30 \mathrm{~s}$ annealing at $55^{\circ} \mathrm{C}$, and $30 \mathrm{~s}$ extension at $72^{\circ} \mathrm{C}$. The final extension was $10 \mathrm{~min}$ at $72^{\circ} \mathrm{C}$. The mixture was cooled to $4^{\circ} \mathrm{C}$.

The fungal internal transcribed spacer (ITS) fragment was amplified before DGGE analysis using a nested PCR approach with the primer pairs ITS1f $\left(5^{\prime}\right.$-CTTGGTCATTTAGAGGAAGTAA-3')/ITS4 (5'-TCCTCCGCTTATTGATATGC-3') and ITS1f-GC clamp (5'-CGCCCGCCGCGCGCGGCGGGCGGGGC GGGGGCACGGGGGGCTTGGTCATTTAGAGGAAGTAA-3 $\left.{ }^{\prime}\right) /$ ITS2 $\left(5^{\prime}\right.$ - GCTGCGTTCTTCA TCGATGC- $\left.3^{\prime}\right)^{42}$. First-round PCR was performed in a $25-\mu \mathrm{L}$ volume consisting of $0.25 \mu \mathrm{L}$ ExTaq DNA polymerase (TaKaRa Bio Inc., Kusatsu, Shiga, Japan), $2.5 \mu \mathrm{L}$ of $10 \times$ Ex Taq Buffer (TaKaRa Bio Inc., Kusatsu, Shiga, Japan), $2 \mu \mathrm{L}$ dNTP mix (TaKaRa Bio Inc., Kusatsu, Shiga, Japan), 5 ng extracted soil DNA, $20 \mu \mathrm{M}$ ITS1f, $20 \mu \mathrm{M}$

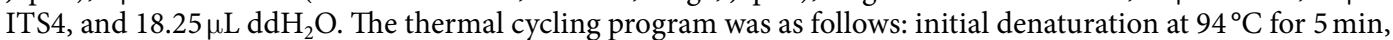
then 35 cycles of $1 \mathrm{~min}$ denaturation at $94^{\circ} \mathrm{C}$, then $45 \mathrm{~s}$ annealing at $50^{\circ} \mathrm{C}$, and $1 \mathrm{~min}$ extension at $72^{\circ} \mathrm{C}$. The final extension was $10 \mathrm{~min}$ at $72^{\circ} \mathrm{C}$. The products served as templates for the second PCR. The reaction mixture for the 
second PCR was the same as that for the first except ITS1f-GC/ITS2 was used instead of ITS1f/ITS4. The PCR conditions were the same as those described for the first PCR except 25 cycles were run instead of 35.

DGGE was conducted with a DCode ${ }^{\mathrm{TM}}$ Universal Mutation Detection System (Bio-Rad Laboratories Inc., Hercules, CA, USA). Twenty microliters of PCR products containing $200 \mathrm{ng}$ DNA were loaded onto $8 \%$ acrylamide gel with a linear chemical gradient ranging from $35-55 \%$ denaturant, where $100 \%$ denaturant $=7 \mathrm{M}$ urea $+40 \%$ formamide $)^{43}$. The polyacrylamide gels were prepared with a Model 475 Gradient Delivery System (Bio-Rad Laboratories Inc., Hercules, CA, USA). The gel electrophoresis was run in $1 \times$ TAE buffer $(40 \mathrm{mM}$ Trisacetate and $1 \mathrm{mM}$ EDTA; $\mathrm{pH} 8.0$ ) for $4 \mathrm{~h}$ at $60^{\circ} \mathrm{C}$ and $150 \mathrm{~V}$ for bacteria and for $17 \mathrm{~h}$ at $60^{\circ} \mathrm{C}$ and $100 \mathrm{~V}$ for fungi. The gels were stained with silver according to the protocol of Radojkovic and Kušic ${ }^{44}$ and captured with a Fluor-S Multi-imager (Bio-Rad Laboratories Inc., Hercules, CA, USA).

Sequence analyses. The intense DGGE bands found in all treatments or bands only found in the combination treatment or CK treatment were excised from the gel with a sterile scalpel under UV illumination. The DNA was eluted overnight at $4^{\circ} \mathrm{C}$ in $20 \mu \mathrm{L}$ sterile water ${ }^{45}$. The excised DNA was then re-amplified with $338 \mathrm{f}$ 1518r and ITS1f/ITS2 as described above. After purification, the DNA fragments were ligated to the pMD18-T cloning vector (TaKaRa Bio Inc., Kusatsu, Shiga, Japan) and transformed into Escherichia coli DH5 $\alpha$ (GenStar Biosolutions Co. Ltd., Beijing, China) according to the manufacturer's instructions. Three positive clones were randomly selected per band for DNA sequencing in a Qingke Biotech (Qingke Co. Ltd., Beijing, China). The resulting sequences were compared by BLAST search (http://www.ncbi.nlm.nih.gov/blast/Blast.cgi) with those in public databases.

Isolation and identification of nematode. Nematodes were extracted from $100 \mathrm{~cm}^{3}$ of rhizospheric soil by the modified salt-centrifugal-flotation technique ${ }^{40}$. The extracted nematodes were immediately fixed according to the method described by Seinhorst ${ }^{46}$. The fixed nematodes were observed under a stereoscopic microscope (SZ61; Olympus Corp., Tokyo, Japan) and identified to the genus level with the identification keys of Yin ${ }^{47}$. Nematodes were assigned to trophic groups (plant parasites, fungivores, bacterivores, or predators/omnivores) according to the method of Yeates ${ }^{48}$. They were also assigned colonizer-persister (c-p) values of $1-5$ corresponding to the positions of their life histories along the colonizer-persister continuum ${ }^{38}$.

Statistical analyses. Data were analyzed in SPSS v. 15.0 (IBM Corp., Armonk, NY, USA). One-way ANOVA followed by Tukey's post hoc test was run to identify significant differences between treatments. Pearson's correlation coefficients were determined for bivariate correlations. Permutational multivariate analysis of variance (PERMANOVA; PRIMER-E/Quest Research Ltd., Auckland, NZ) was used to evaluate statistical significance between DGGE profiles. All statistical tests were performed using 0.05 as the significance level. Soil microbial and nematode population data were log-transformed then subjected to ANOVA.

Banding patterns of the DGGE profile were analyzed in Quantity One v. 4.6.2 (Bio-Rad Laboratories Inc., Hercules, CA, USA).

The total abundance of nematodes per trophic group and the percentage of each trophic group in the nematode community were calculated. The ratio of fungivore to fungivore plus bacterivore $[F /(F+B)]$ was calculated to characterize decomposition and mineralization pathways ${ }^{49}$.

The nematode community structure was determined by the maturity index which was measured based on the life history strategy characteristics of the nematode taxa. The maturity indices were calculated separately for plant parasitic (PPI) and free-living (MI) families ${ }^{38}$ according to formula (1).

$$
\operatorname{MI}(P P I)=\sum_{i=1}^{n} C P i \times P i
$$

where $C P i$ is the colonizer-persister (c-p) value assigned to family $i, P i$ is the proportion of family $i$ per sample., and $n$ is the total number of individuals per sample ${ }^{38}$.

Nematode community diversity was estimated with the Shannon diversity $\left(H^{\prime}\right)$, Margalef richness $(S R)$, and Pielou evenness $\left(E_{H}\right)$ indices according to formulae (2), (3), and (4).

$$
\begin{gathered}
H^{\prime}=\sum_{i=1}^{s} P i(\operatorname{In} P i) \\
E_{H}=\frac{H^{\prime}}{\operatorname{In} S} \\
S R=\frac{S-1}{\ln S}
\end{gathered}
$$

where $P i$ is the proportion of family $i$ in the total nematode community and $S$ is the number of individuals in family $i^{50}$.

Received: 22 January 2019; Accepted: 26 October 2019;

Published online: 15 November 2019

\section{References}

1. Davies, L. J. \& Elling, A. A. Resistance genes against plant-parasitic nematodes: a durable control strategy? Nematology 17, 249-263 (2015).

2. Ismail, A. E. Growing Jatropha curcas and Jatropha gossypiifolia as a interculture with sunflower for control of Meloidogyne javanica in Egypt. International journal of sustainable agricultural research 1, 39-44 (2014). 
3. Rashad, F. M., Fathy, H. M., El-Zayat, A. S. \& Elghonaimy, A. M. Isolation and characterization of multifunctional Streptomyces species with antimicrobial, nematicidal and phytohormone activities from marine environments in Egypt. Microbiological research $175,34-37$ (2015).

4. Saxena, S. Microbial metabolites for development of ecofriendly agrochemicals. Allelopathy Journal 33, 1-24 (2014).

5. Jin, N., Liu, Q. \& Jian, H. Advances on biological control of pant-parasitic nematodes. Chinese journal of biological control 31, 789-800 (2015).

6. Siddiqui, I. A. \& Shaukat, S. S. Trichoderma harzianum enhances the production of nematicidal compounds in vitro and improves biocontrol of Meloidogyne javanica by Pseudomonas fluorescens in tomato. Letters in applied microbiology 38, 169-175 (2004).

7. Talibi, I., Boubaker, H., Boudyach, E. H. \& Ait Ben Aoumar, A. Alternative methods for the control of postharvest citrus diseases. Journal of applied microbiology 117, 1-17 (2014).

8. Li, G. J. et al. Management of Meloidogyne incognita on tomato with endophytic bacteria and fresh residue of Wasabia japonica. Journal of applied microbiology 117, 1159-1167 (2014).

9. Jin, N. et al. Field evaluation of Streptomyces rubrogriseus HDZ-9-47 for biocontrol of Meloidogyne incognita on tomato. Journal of Integrative Agriculture 16, 1347-1357 (2017).

10. Somasekhar, N., Grewal, P. S., De Nardo, E. A. B. \& Stinner, B. R. Non-target effects of entomopathogenic nematodes on the soil nematode community. Journal of applied ecology 39, 735-744 (2002).

11. Johansen, A., Olsson, S. \& Hendriksen, N. B. Soil microbial community shows transient responses after addition of the biological control agent Pseudomonas fluorescens DR54 at a range of cell densities. Applied soil ecology 3, 75-84 (2015).

12. Mazzola, M., Granatstein, D. M., Elfving, D. C., Mullinix, K. \& Gu, Y. H. Cultural management of microbial community structure to enhance growth of apple in replant soils. Phytopathology 92, 1363-1366 (2002).

13. Berg, G., Zachow, C., Cardinale, M. \& Müller, H. Ecology and human pathogenicity of plant-associated bacteria in Regulation of biological control agents (ed. Ehlers, R. U.) 175-189 (Springer Netherlands, 2011).

14. Henderson, D. R., Riga, E., Ramirez, R. A., Wilson, J. \& Snyder, W. E. Mustard biofumigation disrupts biological control by Steinernema spp. nematodes in the soil. Biological control 48, 316-322 (2009).

15. Wang, Q. J. et al. Integration of biofumigation with antagonistic microorganism can control Phytophthora blight of pepper plants by regulating soil bacterial community structure. European journal of soil biology 61, 58-67 (2014).

16. Valdes, Y., Viaene, N. \& Moens, M. Effects of yellow mustard amendments on the soil nematode community in a potato field with focus on Globodera rostochiensis. Applied soil ecology 59, 39-47 (2012).

17. Prévost, K., Couture, G., Shipley, B., Brzezinski, R. \& Beaulieu, C. Effect of chitosan and a biocontrol Streptomycete on field and potato tuber bacterial communities. BioControl 51, 533-546 (2006).

18. Sun, M. H., Gao, L., Shi, Y. X., Li, B. J. \& Liu, X. Z. Fungi and actinomycetes associated with Meloidogyne spp. eggs and females in China and their biocontrol potential. Journal of invertebrate pathology 93, 22-28 (2006).

19. Twinn, D. C. Nematodes. Biology of plant litter decomposition 2, 421-465 (1974).

20. Meyer, S. L. F. \& Roberts, D. P. Combinations of biocontrol agents for management of plant-parasitic nematodes and soilborne plantpathogenic fungi. Journal of nematology 34, 1 (2002).

21. Liu, J. B., Sun, J. Z., Qiu, J. Y., Liu, X. Z. \& Xiang, M. C. Integrated management of root-knot nematodes on tomato in glasshouse production using nematicides and a biocontrol agent, and their effect on soil microbial communities. Nematology 16, 463-473 (2014).

22. Zhou, S. Y. et al. A uninucleate Rhizoctonia sp. from maize plant with ITS heterogeneity and hypersensitive to abiotic stresses. European journal of plant pathology 142, 397-401 (2015).

23. Wu, K. et al. Effects of bio-organic fertilizer plus soil amendment on the control of tobacco bacterial wilt and composition of soil bacterial communities. Biology and fertility of soils 50, 961-971 (2014).

24. Gao, G. P. et al. Effect of biocontrol agent Pseudomonas fluorescens 2P24 on soil fungal community in cucumber rhizosphere using T-RFLP and DGGE. PloS one, 7 (2012).

25. Du, W. et al. Effects of Beauveria bassiana and acephate on enzyme activities and microbial diversity in paddy soil. Plant, soil and environment 59, 562-567 (2013).

26. Ascencion, L. C., Liang, W. J. \& Yen, T. B. Control of Rhizoctonia solani damping-off disease after soil amendment with dry tissues of Brassica results from increase in Actinomycetes population. Biological Control 82, 21-30 (2015).

27. Todd, T. C. Effects of management practices on nematode community structure in tallgrass prairie. Applied soil ecology 3, 235-246 (1996).

28. Georgieva, S. S., McGrath, S. P., Hooper, D. J. \& Chambers, B. S. Nematode communities under stress: the long-term effects of heavy metals in soil treated with sewage sludge. Applied soil ecology 20, 27-42 (2002).

29. Treonis, A. M. et al. Effects of organic amendment and tillage on soil microorganisms and microfauna. Applied soil ecology 46, 103-110 (2010).

30. Gruver, L. S., Weil, R. R., Zasada, I. A., Sardanelli, S. \& Momen, B. Brassicaceous and rye cover crops altered free-living soil nematode community composition. Applied soil ecology 45, 1-12 (2010).

31. Thoden, T. C., Korthals, G. W. \& Termorshuizen, A. J. Organic amendments and their influences on plant-parasitic and free-living nematodes: a promising method for nematode management. Nematology 13, 133-153 (2011).

32. Reardon, C. L., Strauss, S. L. \& Mazzola, M. Changes in available nitrogen and nematode abundance in response to Brassica seed meal amendment of orchard soil. Soil biology and biochemistry 57, 22-29 (2013).

33. Bongers, T. The maturity index: an ecological measure of environmental disturbance based on nematode species composition. Oecologia 83,14-19 (1990).

34. Yin, D. H., Wang, N., Xia, F., Li, Q. \& Wang, W. Impact of biocontrol agents Pseudomonas fluorescens 2P24 and CPF10 on the bacterial community in the cucumber rhizosphere. European Journal of Soil Biology 59, 36-42 (2013).

35. Scherwinski, K., Wolf, A. \& Berg, G. Assessing the risk of biological control agents on the indigenous microbial communities: Serratia plymuthica HRO-C48 and Streptomyces sp. HRO-71 as model bacteria. Biocontrol 52, 87-112 (2007).

36. PolKa, J. et al. Bacterial diversity in typical Italian salami at different ripening stages as revealed by high-throughput sequencing of $16 \mathrm{~S}$ rRNA amplicons. Food Microbiology 46, 342-356 (2015).

37. Neilson, J. W., Jordan, F. L. \& Maier, R. M. Analysis of artifacts suggests DGGE should not be used for quantitative diversity analysis. Journal of Microbiological Methods 92, 256-263 (2013).

38. Bridge, J. \& Page, S. L. J. Estimation of root-knot nematode infestation levels on roots using a rating chart. International journal of pest management 26, 296-298 (1980).

39. Jian, H., Yang, H. W. \& Zhang, N. X. An improvement of centrifugal flotation method to recover entomopathogenic nematode from soil. Chinese journal of biological control 11, 4 (1995).

40. Semenov, A. M., van Bruggen, A. H. C. \& Zelenev, V. V. Moving waves of bacterial populations and total organic carbon along roots of wheat. Microb Ecol 37, 116-128 (1999).

41. Muyzer, G., De Waal, E. C. \& Uitterlinden, A. G. Profiling of complex microbial populations by denaturing gradient gel electrophoresis analysis of polymerase chain reaction-amplified genes coding for $16 \mathrm{~S}$ rRNA. Applied and environmental microbiology 59, 695-700 (1993)

42. Weinert, N. et al. Rhizosphere communities of genetically modified zeaxanthin-accumulating potato plants and their parent cultivar differ less than those of different potato cultivars. Applied and environmental microbiology 75, 3859-3865 (2009). 
43. Van Elsas, J. D., Duarte, G. F., Keijzer-Wolters, A. \& Smit, E. Analysis of the dynamics of fungal communities in soil via fungalspecific PCR of soil DNA followed by denaturing gradient gel electrophoresis. Journal of microbiological methods 43, 133-151 (2000).

44. Radojkovic, D. \& Kušic, J. Silver staining of denaturing gradient gel electrophoresis gels. Clinical chemistry 46, 883-884 (2000).

45. Nikolausz, M., Sipos, R., Revesz, S., Szekely, A. \& Marialigeti, K. Observation of bias associated with re-amplification of DNA isolated from denaturing gradient gels. FEMS microbiology letters 244, 385-390 (2005).

46. Seinhorst, J. W. A rapid method for the transfer of nematodes from fixative to anhydrous glycerin. Nematologica 4, 67-69 (1959).

47. Yin, W. J. Pictorial keys to soil animal of China (ed. Yin, W. J.) 39-43 (Science Press, 1998).

48. Yeates, G. W., Bongers, T., De Goede, R. G. M., Freckman, D. W. \& Georgieva, S. S. Feeding habits in soil nematode families and genera-an outline for soil ecologists. Journal of nematology 25, 315 (1993).

49. Freckman, D. W. \& Ettema, C. H. Assessing nematode communities in agroecosystems of varying human intervention. Agriculture, Ecosystems \& Environment 45, 239-261 (1993).

50. Ludwig, J. A. \& Reynolds, J. F. Statistical ecology: a primer on methods and computing (eds Ludwig, J. A. \& Reynolds, J. F.) 337-339 (Wiley, 1988).

\section{Acknowledgements}

This work was supported by the National Key Research and Development Program of China (Grant Nos 2017YFD0200601, 2018YFD0201201), the National Natural Science Foundation of China (Grant Nos 31571987, 31772138), and the Agro-Scientific Research of the Public Interest of the People's Republic of China (Grant No. 201103018).

\section{Author contributions}

H.J. and N.J. designed the experiments and wrote the manuscript. N.J., X.L., and X.W. performed the experiments. N.J., Q.L., D.P., and H.J. analyzed the results. All authors read and approved the final manuscript.

\section{Competing interests}

The authors declare no competing interests.

\section{Additional information}

Supplementary information is available for this paper at https://doi.org/10.1038/s41598-019-52941-9.

Correspondence and requests for materials should be addressed to H.J.

Reprints and permissions information is available at www.nature.com/reprints.

Publisher's note Springer Nature remains neutral with regard to jurisdictional claims in published maps and institutional affiliations.

Open Access This article is licensed under a Creative Commons Attribution 4.0 International License, which permits use, sharing, adaptation, distribution and reproduction in any medium or format, as long as you give appropriate credit to the original author(s) and the source, provide a link to the Creative Commons license, and indicate if changes were made. The images or other third party material in this article are included in the article's Creative Commons license, unless indicated otherwise in a credit line to the material. If material is not included in the article's Creative Commons license and your intended use is not permitted by statutory regulation or exceeds the permitted use, you will need to obtain permission directly from the copyright holder. To view a copy of this license, visit http://creativecommons.org/licenses/by/4.0/.

(C) The Author(s) 2019 